\title{
Solar-assisted heat pump coupled to solar hybrid panels
}

\author{
A. Martínez-Gracia ${ }^{1}$, A. Del Amo ${ }^{2}$, S. Torné ${ }^{3}$, A. Bayod-Rújula ${ }^{4}$, J. Uche ${ }^{1}$, S. Usón ${ }^{1}$ \\ ${ }^{1}$ Department of Mechanical Engineering \\ CIRCE Institute., University of Zaragoza \\ Campus Río Ebro - Zaragoza, María de Luna, 550018 Zaragoza (Spain)
}

Phone/Fax number:+0034 976 761913, e-mail: amayamg@unizar.es, javiuche@unizar.es, suson@unizar.es

${ }^{2}$ Abora Solar S.L. Advanced solar energy. Spain.

Buenos Aires 117. Polígono Centrovía. 50196 La Muela, Zaragoza (Spain)

adelamo@abora-solar.com, marta.canada@abora-solar.com

${ }^{3}$ Ingeniería Torné. Spain.

Paseo Longares, 7, 50014 Zaragoza

sergiotorne@itorne.com

${ }^{4}$ Department of Electrical Engineering

CIRCE Institute., University of Zaragoza

Campus Río Ebro - Zaragoza, María de Luna, 550018 Zaragoza (Spain)

Phone/Fax number:+0034 976 761913, e-mail: aabayod@unizar.es

\begin{abstract}
.
A water-water solar-assisted heat pump (SAHP) is going to be installed on an academic building at the University of Zaragoza (Spain). It integrates a heat pump heating system with photovoltaics/thermal collectors and seasonal storage. Considerably higher performances than a conventional type airsource heat pump are expected to be reached.

This paper shows the simulation of the system performed in trnsys, a graphically based software used to simulate the behaviour of transient systems. The obtained energy and monetary savings are analysed
\end{abstract}

\section{Key words}

Photovoltaic/thermal hybrid solar modules, Solar assisted heat pump, seasonal storage

\section{Introduction}

Heating and cooling demands constitute nowadays a significant part of the energy needs of our society, especially in domestic and tertiary sectors. Solar energy can clearly help to meet those requirements, but their widespread use depends on the development of costeffective and high-efficient systems. A PVT panel is a module that simultaneously produces both heat and electricity; its overall efficiency is higher than that of independent PV and solar thermal systems. In these systems, the unutilized part of incoming solar radiation by the PV module in the form of heat is extracted by the cooling medium (air, water or refrigerant) for practical applications. The join installation of heat pumps and photovoltaics/thermal (PVT) collectors presents those characteristics, since the solar energy can provide a heat source at a higher temperature level than atmospheric conditions in winter season. It favours the operation of the heat pump. The coefficient of performance (COP) of a heat pump therefore increases and the temperature of the collector is reduced, so the heat loss from the collector to the surroundings decreases, resulting in higher collector efficiencies.

Combination of solar thermal collectors and heat pump in a single solar assisted heat pump (SAHP) system has been widely used for various purposes including water heating. There exists a growing interest towards most effective use of solar heat pump systems for residential use, as indicated by the International Energy Agency through the Task44 of the Solar Heating and Cooling (SHC) Programme. The Task aimed at optimizing combinations of solar thermal energy and heat pump, primarily for one family houses (IEA, 2013). That is, one of the items in focus were small-scale residential heating and hot water systems that use heat pumps and any type of solar thermal collectors as the main components.

Currently, Task 60 (IEA, 2018) is focused on the application of PVT collectors in order to assess existing solutions and to develop new system solution principles in which the PVT technology really offers advantages over the classical "side by side installations" of solar thermal collectors and PV modules. Energy production, competitive cost, safety and reliability of systems are being considered within this task. 
During the last decade, there have been numerous contributions regarding SAHP systems for low ed out a complete and systematic review. Most of the literature refers to conventional solar collectors (Wang et al, 2017; Bellos and Tzivanidis, 2017), although also the solar hybrid PVT panels are being considered (Bertram et al, 2012; Kim et al, 2014; Antoñanzas et al, 2015; Buker and Riffat, 2016; Del Amo et. Al, 2017). They present important advantages such as the room saving on the roof and the efficiency. PVT technology is also well documented in literature, with interesting studies even in poligeneration schemes (Usón et al, 2019; Uche el al, 2019).

The HP+PVT coupling can be implemented both at small or large scale. A study for heating an industrial building was presented by Del Amo et al. (2019), although the seasonal storage was not included. This paper focuses on the case study of a solar-assisted heat pump (SAHP) fed by photovoltaic-thermal collectors and including seasonal storage in an academic building at the University of Zaragoza. The final target would be to guide the energy policy towards the large-scale implementation of solarassisted heat pumps.

The system concept is schematically shown in Figure 1. The main three elements of the configuration are the hybrid solar field, the seasonal storage and the heat pump. The hybrid solar panel generates electricity and hot water with a single device. Hot water is accumulated in a seasonal reservoir and electricity is self-consumed by both the heat pump and other uses of the building. The seasonal storage stores the surplus heat collected during the summer months to be delivered along the winter season when the highest heating demands occur. This accumulation makes it possible to achieve significantly higher solar contributions due to its availability at any time of the year. The water-water heat pump extracts the heat from the seasonal accumulator and heats two discharge circuits: the heating circuit and the DHW circuit.



Fig. 1 Schema of the PVT+HP+Storage coupling

\section{Methodology}

Although the work presented in this paper is framed within a global refurbishment project including many other energy saving measures, only the aspects directly related to the described energy system where considered. The analysis started with the study of the thermal demand for heating in the building.

Each component of the energy system was analysed and sized according to the legal requirements and the correct temperature applications. Bukert (2016) carri

coupling of the different parts of the generation and consumption sides.

Weather and climatic data, demand profiles as well as the different devices were introduced in the simulation software. The model was elaborated in Trnsys, a reference transient systems simulation software with modular structure, mainly applied on renewable energy systems analysis. It also includes additional libraries for low energy buildings and HVAC systems, cogeneration and fuel cells. Additionally, many of the components commonly found in thermal and electrical energy systems, as well as component routines to handle input of weather data or other time-dependent forcing functions and output of simulation results. Since solar systems are highly dependent of the passage of time, TRNSYS is well suited to detailed analyses of them.

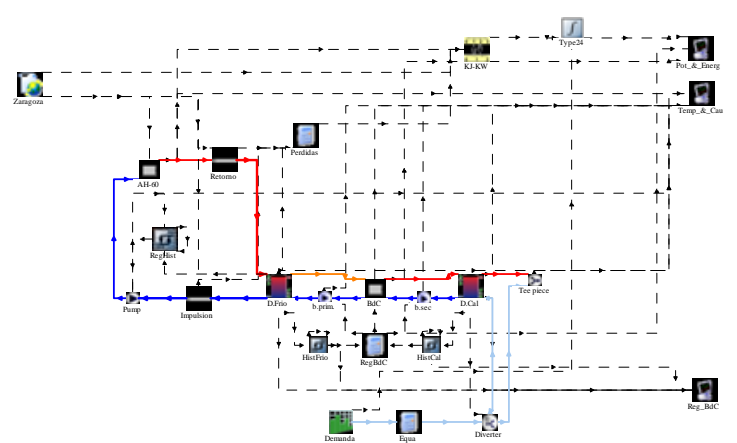

Fig. 2 Simplified trnsys simulation

Because of their physic behaviour, the combination of PVT with a water-water heat pump is very convenient: the operating conditions of both systems make suitable their coupling. PVT collectors operate better the lower their working temperatures are: thermal efficiency is higher in these conditions because the convection losses are considerably lower; and at the same time the electrical efficiency is also higher because of the PV cells are cooler. Since the absorber plate is together the PV cells, the temperature of the cells will be lower as lower is the working temperature of the flow in the solar circuit. Conversely, when the heat pump is operating in heating mode, its behaviour improves with high temperature because the higher temperature of the cold storage diminishes the compressors consumption.

Therefore, there exists an optimum operating point in the coupling. Such a point is not easy to determine since it requires an annual simulation to analyse the temperature of the three-way valve that maximizes production by modifying the inlet water temperature on the condenser. This study requires the dynamic simulation carried out in this work.

The heat pump provides the heat flow (QHP) feeding the heating circuit of the building. The low-temperature heat flow introduced in the heat pump comes from the solar seasonal deposit storage and constitutes the cold side of the heat pump The electricity flow demanded by the HP (WHP) depends on the system operation at each step; temperatures of the evaporator and of the condenser are 
the key variables. Clearly, the operation characteristics of the heat pump are provided by the manufacturer and introduced in the simulation.

The electricity provided by the PVT panels feeds the HP (WPVtoHP). At each step of time, it may happen that the production WPVT was higher or lower than the HP electricity demand. Then, if WPVT exceeds WPVtoHP, the extra electricity goes to other electricity consumers in the building and this amount of energy is denoted as WtoGRID. It may alternatively happen the opposite situation: the variable WfromGRID is therefore defined. To sum up, two basic electrical energy balances are stated accordingly:

$$
\begin{aligned}
& W_{D V T}^{X}-W_{P V \text { toHP }}+\psi_{\text {tQGRN }} \\
& W_{E y}=W_{k \text { troky }}+W_{t \text { romGnu }}
\end{aligned}
$$

Equation (1) indicates that the electricity production of the PVT panels meets the HP electricity demand and may eventually feed other demands as well. Equation (2) is focused on the HP electricity demand and states that it is covered by the photovoltaic production in the PVT devices and, if required, taken from the network. The contracted power in the industry where the system is located is 100 $\mathrm{kW}$, so the total electricity produced in situ is assumed to be consumed.

The background analysis of the system is based on the basic performance equations of its main component: the heat pump and the PVT panels. The HP is operating in heating mode, demanding electrical energy to run the mechanical compressor and providing a heat source at high temperature to produce domestic hot water. The coefficient of performance of the heat pump is a measurement of its efficiency (Equation 3).

$$
C O P=\frac{Q_{H E}}{W_{H F}}
$$

The PVT panels produce simultaneously heat and electricity according to the specifications provided by the manufacturer. The thermal performance is defined by the panel thermal yield and the design of the system. The instantaneous efficiency varies with the operating conditions according to Equation (4):

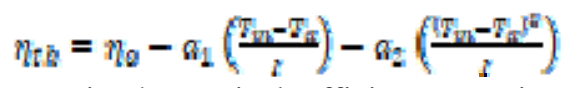

where $\eta_{0}$ is the optical efficiency, $a_{1}$ is the heat loss coefficient, $a_{2}$ is the temperature dependence of the heat loss coefficient, I is the global solar irradiance, Ta is the ambient temperature and $\mathrm{Tm}$ is defined as the average temperature between the input and output temperatures. The variables in brackets are commonly abbreviated as $\mathrm{T}^{*}$ $\left(\mathrm{T}^{*}=(\mathrm{Tm}-\mathrm{Ta}) / \mathrm{I}\right)$.

The electricity production of the PV cells encapsulated in the PVT panel depends on the solar irradiation and the cell temperature Tc, as well as on the physical features of the photovoltaic material. Equation (5) determines the power delivered by the PV modules considering the peak power of the module $\left(\mathrm{P}_{\mathrm{n}}\right)$, the solar irradiance $(\mathrm{I})$, the temperature coefficient losses $(\gamma)$ and the cell temperature $\left(T_{c}\right)$.

$$
W_{P Y T}=P_{n}^{P} \cdot \frac{i}{1000} \cdot\left[1-\psi \cdot\left(T_{\sigma}-25\right)\right]
$$

The cell temperature is directly connected to the temperature of the absorber plate, that is, to the temperature of the flow going in and out of the panel. This is a fundamental difference between the conventional PV modules and the PVT ones, since the temperature at which the cell is operating is determined by the flow in the solar circuit.

The solar coverage is calculated by comparing the heat produced by the solar field, excluding the losses in pipes and storage, to the demand of the building.

\section{Case Study}

The SAHP is currently being installed in an academic building at the University of Zaragoza. The different rooms organize in three floors, with a total surface of $6700 \mathrm{~m}^{2}$, comprising classrooms, meeting rooms, offices, central floor and corridors, auxiliary spaces... The solar system comprises 105 PVT panels and 200 conventional PV panels (Fig. 3 ), with a seasonal storage of $300 \mathrm{~m}^{3}$. The system is devoted to provide heating for the building and the PV production is expected to be self-consumed both by the HP and the other electrical demands of the facility. There exit additional operation strategies to meet the heat demand when the storage runs out. The heat pump may operate with geothermal.

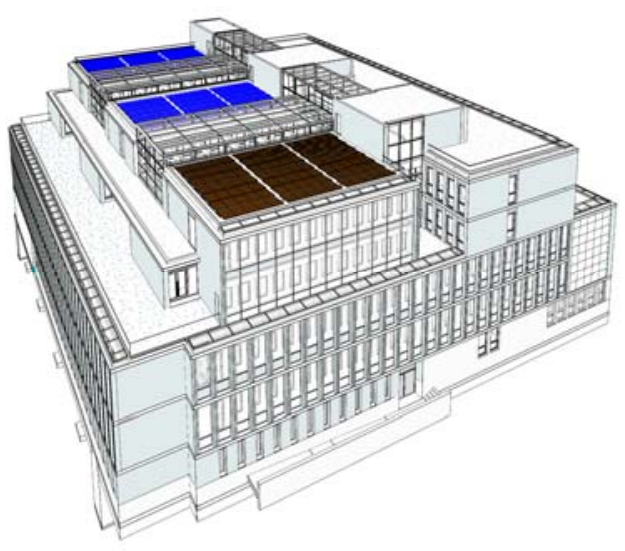

Figure 3. Location of the PVT (brown) and PV panels (blue) on the roof of the building.

The hybrid solar field, south-faced and with a slope of $37^{\circ}$, is composed by aH-60 panels $\left(1.65 \mathrm{~m}^{2}\right.$ total area), manufactured in Zaragoza by Abora Solar. Each panel has a rated power of $260 \mathrm{~W}_{\mathrm{p}}$ with $60 \mathrm{PV}$ cells; the thermal specifications are: 0.59 for the optical performance and $3.3 \mathrm{~W} / \mathrm{m}^{2} \mathrm{~K}$ and 0.018 $\mathrm{W} / \mathrm{m}^{2} \mathrm{~K}^{2}$ for the coefficients of thermal losses, $\mathrm{a}_{1}$ and $\mathrm{a}_{2}$ respectively. The performance provided by the manufacturer is shown in Figure 4, where $T_{m}$ is the average temperature of the fluid in the collector, $T_{a}$ is the environment temperature and $G$ is the solar irradiance. 


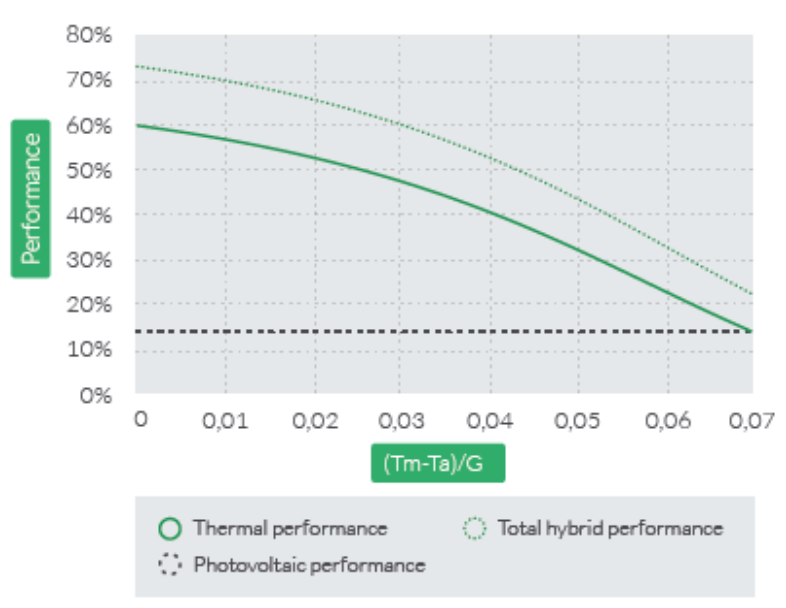

Figure 4. Performance of the hybrid panel aH-60 (source: Abora Solar)

The $300 \mathrm{~m}^{3}$ storage tank is buried just below the main hall of the building and storages the surplus of solar energy collected by the panels. It constitutes de cold side in the operation of the $29 \mathrm{~kW}_{\mathrm{t}}$ water-water heat pump which is included in the project. There exists a small back up hot storage tank of $10 \mathrm{~m}^{3}$ to support the consumption side.

The heating option for the building is a water-based radiant floor system. It provides heating in a room from the floor up for consistent, efficient warmth: warm water systems run hot water through pipes to create the heat transfer. Figure 5 presents the heating demand profile in the building along the year. The building yearly demands $164,364 \mathrm{kWh}$ for heating.

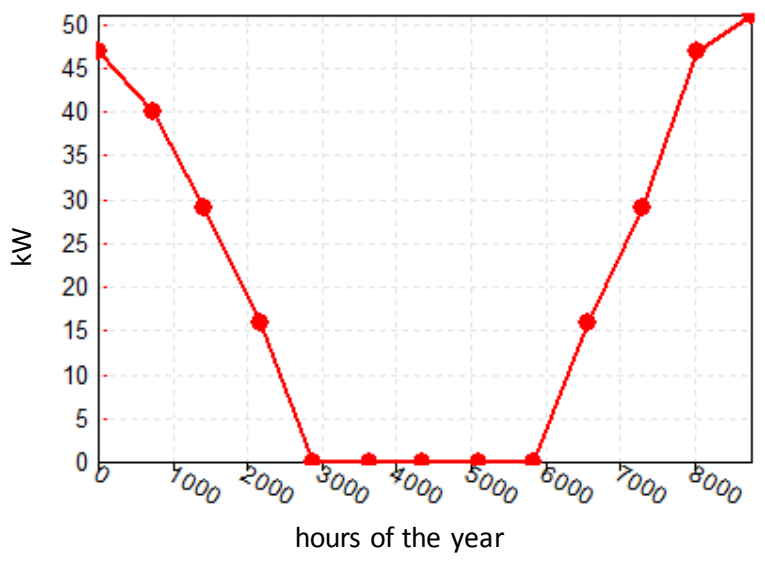

Figure 5. Heating demand profile

\section{Results and discussion}

The solar irradiance on the panels is $1,597 \mathrm{kWh} / \mathrm{m}^{2} / \mathrm{yr}$. It means that the total raw solar energy input on the system is about 269,973 kWh/yr. Since que thermal and electrical production of the PVT field are 90,473 and 38,981 kWh/yr respectively, thermal yield rises up to $33 \%$ while electrical yield reaches $14.4 \%$.

The evolution of the temperatures within the seasonal storage (top and bottom of the deposit) can be observed in Fig. 5. Temperature of the storage ranges from 10 to $65^{\circ} \mathrm{C}$, what means an amplitude of $55^{\circ} \mathrm{C}$. The charge (summer) and discharge (winter) periods can be easily identified: charging period starts in spring, when there already exists a surplus of the catchment of thermal energy versus the heating demand.

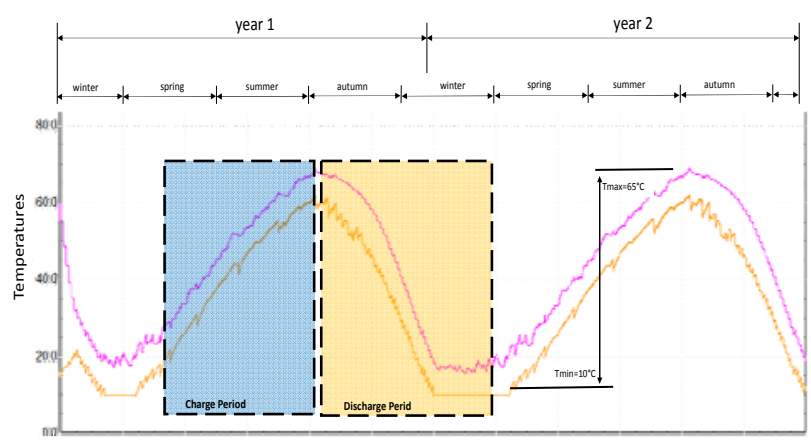

Figure 6. Temperature profiles of the seasonal storage.

The $95 \%$ of the electricity produced by the PVT field leaves the inverter as alternating current to fed the HP $(4,472 \mathrm{kWh} / \mathrm{yr})$ as well as any other electrical requirements of the building or being delivered to the grid $(32,560 \mathrm{kWh} / \mathrm{yr})$. As a whole, $12 \%$ of the renewable electricity produced by the system is directly consumed by the HP. It means the $28 \%$ of the electricity demand of the HP.

The solar coverage rate, that is, the percentage of the amount of energy for heating that is provided by the sun is $26 \%$ (Figure 7 ).

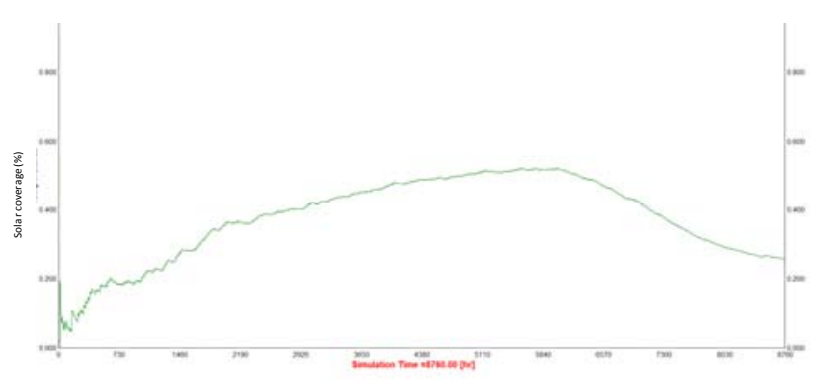

The total investment for the seasonal storage system is estimated in $138.650 €$. Considering the expected savings, it yields to a payback period of 6,6 years.

Further considerations regarding the initial design of the system and the simulation model could be improved. The ratio between the catchment area and the water storage volume is around $1.8 \mathrm{~m}^{3} / \mathrm{m}^{2}$, which is clearly quite low. This fact strictly corresponds to economic reasons derived from the project. Better global results could be found by increasing that relationship.

The demand has been defined in a continuous web, as shown in Figure 5. Control strategies could modify such demand in order to avoid the operation of the HP at night. 


\section{Conclusion}

A complete model to simulate SAHP with PVT panels and seasonal storage has been presented. Results indicate that, in a first step, to optimize the basic parameters of the sizing is a key point in the analysis. The simulation allows describing the expected performance of the system. Additionally, this tool constitutes a powerful tool for the industry developing and selling the equipment, as well as to the research on the energy efficiency and renewable energies integration field.

Specifically, it is clear that when there is a higher temperature in the accumulation than in air or soil, the COP of the heat pump is higher than in the rest of the technologies.

The seasonal storage facilitates the operation of the HP with lower electricity demand, both because of the higher temperature on the cold focus and because of the electricity produced by the PV devices.

\section{Acknowledgement}

The authors gratefully acknowledge the financial support provided by the University of Zaragoza (Spain) in the framework of the Proyectos de Investigacion Program, under the AE-SAHP (UZ2018-TEC-07) project Additionally, authors would like to acknowledge the collaboration of Abora Solar SL, Ingenieria Torné and the Infrastructure Section of the University of Zaragoza in the development of this work.

\section{References}

[1] Abora Solar, 2018. Abora aH60 Data sheet. https://abora-

solar.com/descargas/DS\%20AH60\%20OPTIMUM.pdf

[2] Antonanzas J, del Amo A, Martínez-Gracia A, BayodRujula AA and Antonanzas-Torres F. (2015) Towards the optimization of convective losses in photovoltaicthermal panels. Solar Energy 116 pp. 323-336. https://doi.org/10.1016/j.solener.2015.04.013

[3] Bellos E, Tzivanidis C (2017). Energetic and financial sustainability of solar assisted heat pump heating systems in Europe. Sustainable Cities and Society, 33 pp. 70-84. https://doi.org/10.1016/j.scs.2017.05.020

[4] Buker MS, Riffat SB (2016). Solar assisted heat pump systems for low temperature water heating applications: A systematic review. Renewable and Sustainable Energy Reviews 55, pp. 399-413. https://doi.org/10.1016/j.rser.2015.10.157

[5] Chow TT, Pei G, Fong KF, Lin Z, Chan ALS and He $M$ (2010). Modeling and application of directexpansion solar-assisted heat pump for water heating in subtropical Hong Kong. Applied Energy, 87 (2) pp. 643-649. https://doi.org/10.1016/j.apenergy.2009.05.036.

[6] Del Amo, A., Martínez-Gracia, A., Bayod-Rújula, A.A., Antoñanzas, J. (2017). An innovative urban energy system constituted by a photovoltaic/thermal hybrid solar installation: Design, simulation and monitoring. Applied Energy, 186 pp. 140-151 https://doi.org/10.1016/j.apenergy.2016.07.011
[7] Del Amo A, Martínez-Gracia A, Bayod-Rújula A, Cañada M. (2019). Performance analysis and experimental validation of a solar-assisted heat pump fed by photovoltaic-thermal collectors. Energy 169, pp. 1214-1223. https://doi.org/10.1016/j.energy.2018.12.117

[8] Gunasekar N, Mohanraj $M$ and Velmurugan V (2015). Artificial neural network modeling of a photovoltaic-thermal evaporator of solar assisted heat pumps. Energy, 93 pp. 908-922. https://doi.org/10.1016/j.energy.2015.09.078

[9] Hassan HZ, Mohamad AA, Bennacer R (2011). Simulation of an adsorption solar cooling system. Energy, $36 \quad$ pp. 530-537. https://doi.org/10.1016/j.energy.2010.10.011

[10] IEA, 2013. Solar and Heat Pump Systems. Solar Heating and Cooling Program. International Energy Agency. http://task44.iea-shc.org/

[11] IEA, 2018. PVT Systems: Application of PVT Collectors and New Solutions in HVAC Systems. Solar Heating and Cooling Program. International Energy Agency. http://task60.iea-shc.org/

[12] Kong X, Jiang K, Dong S, Li Y and Li J (2018). Control strategy and experimental analysis of a directexpansion solar-assisted heat pump water heater with R134a, Energy, 145 pp. 17-24. https://doi.org/10.1016/j.energy.2017.12.114

[13] Lee SJ, Shon BH, Jung CW and Kang YT (2018). A novel type solar assisted heat pump using a low GWP refrigerant (R-1233zd(E)) with the flexible solar collector. Energy, 149 pp. 386-396. https://doi.org/10.1016/j.energy.2018.02.018

[14] Usón S, Uche J, Martínez-Gracias, A, Del Amo A, Acevedo A, Bayod A. (2019). Exergy assessment and exergy cost analysis of a renewable-based and hybrid trigeneration scheme for domestic water and energy supply. Energy. Volume 168, 1 February 2019, Pages 662-683. https://doi.org/10.1016/j.energy.2018.11.124

[15] Uche J, Acevedo L, Círez F, Usón S, Martínez-Gracia A, Bayod.Rújula A. (2019). Analysis of a domestic trigeneration scheme with hybrid renewable energy sources and desalting techniques. Journal of Cleaner Production. Volume 212, 1 March 2019, Pages 14091422. https://doi.org/10.1016/j.jclepro.2018.12.006 